\title{
Behçet's syndrome and relationship with the ratio of insulin-like growth factor-1 (IGF-1)/IGF-binding protein-3 (IGFBP-3)
}

\author{
Özlem Doğan'1 , Emine Ünal², Üçler Kısa³ , Nurkan Aksoy
}

'Department of Biochemistry, Medical School, Ankara University, Ankara, Turkey ${ }^{2}$ Department of Dermatology, Yıldırım Beyazıt University, Yenimahalle Training and Research Hospital, Ankara, Turkey ${ }^{3}$ Department of Biochemistry, Medical School, Kırıkkale University, Kırıkkale, Turkey ${ }^{4}$ Department of Biochemistry, Yıldırım Beyazıt University, Yenimahalle Training and Research Hospital, Ankara, Turkey

Adv Dermatol Allergol 2019; XXXVI (3): 295-301 DOI: https://doi.org/10.5114/ada.2019.85640

\begin{abstract}
Introduction: Behçet's syndrome (BS) is a chronic inflammatory disease with unknown aetiology. Insulin-like growth factor-1 (IGF-1) and IGF-binding protein-3 (IGFBP-3) have important metabolic properties such as anabolic, cytoprotective and anti-inflammatory effects. Circulating IGF-1 and IGF-1/IGFBP-3 concentrations are associated with adiposity and insulin resistance.

Aim: To determine whether serum IGF-1 and IGFBP-3 levels or IGF-1/IGFBP-3 ratio were associated with the presence or activity of BS.

Material and methods: Forty patients with BS (mean age: $39.6 \pm 10$ ), and 20 healthy volunteers (mean age: $37 \pm 10.4$ ) were enrolled. Serum IGF-1, IGFBP-3, and high sensitive C-reactive protein (hs-CRP) and erythrocyte sedimentation rate (ESR) levels were measured in all subjects.

Results: Mean IGF-1 levels were low in both active BS and remission BS compared to the control group and mean IGF-1 levels were similar in active BS and remission BS. In active BS, mean IGFBP-3 levels were higher than in the control group and remission BS. There were positive correlations between these inflammatory cytokines and IGFBP-3 levels. IGF-1/IGFBP-3 ratio was lower in patients with BS compared to the healthy volunteer group, which was statistically significant. IGF-1/IGFBP-3 ratio was lower in BS than in the control group independently of ESR and hs-CRP. Conclusions: IGF-1 may play a diagnostic role to present itself in BS. IGF-1/IGFBP-3 ratio is not useful as an activation or remission criterion. The ratio may be a useful marker to predict the risk of BS presence in the critical population.
\end{abstract}

Key words: Behçet's syndrome, insulin like growth factor-1, IGF-binding protein-3, inflammation.

\section{Introduction}

Behçet's syndrome (BS) is associated with chronic immuno-inflammatory disease that affects several organs. The major clinical symptom is recurrent aphthous ulcer. There may be ocular inflammation, rheumatologic, gastrointestinal and skin involvement, and neurological symptoms and vascular complications may lead to a considerable level of morbidity. Its aetiology is not fully known yet. Pro-inflammatory cytokines such as interleukin (IL)-1, IL-6, IL-8, and tumor necrosis factor $\alpha$ (TNF- $\alpha$ ) are elevated in BS patients and are closely associated with the clinical symptoms and disease activity in BS. Behçet's syndrome has several clinical manifestations, may resemble the monogenic autoinflammatory disorders, and show abnormally increased inflammatory response. Human leukocyte antigen (HLA)-B51 is the strongest sus- ceptibility factor described so far which increases the disease risk and typical phenotype [1-4]. Insulin resistance has been suggested as an etiological factor in BS [3, 5-7].

The insulin-like growth factors (IGFs) are natural peptides, which have similar structural homology with insulin. IGFs circulate in plasma and form complexes into a family of structurally related binding proteins. These are called IGF-binding proteins (IGFBPS) [8]. IGF-1 is primarily synthesized in the liver and forms a primary response to $\mathrm{GH}$. Insulin-like growth factor binding protein-3 (IGFBP-3) is one of the six secretory glycoproteins of the IGFBP family. IGFBP-3 is a major regulator of IGF-1 and IGF-2 [9, 10]. IGFBP-1 and IGFBP-3 occur in all human body fluids, such as amniotic fluid, serum, placenta, endometrium, milk, urine, synovial fluid, interstitial fluid, and seminal fluid [8]. It is known that the differences in the IGF system are

Address for correspondence: Özlem Doğan MD, Department of Biochemistry, Medical School, Ankara University, Ankara, Turkey, phone: +90 532 711968, e-mail: ozlemceylandogan@gmail.com Received: 26.02.2018, accepted: 20.03.2018. 
indeed important in the regulation of glucose homeostasis $[11,12]$. IGF-1 and its primary binding protein IGFBP-3 have important metabolic properties such as anabolic, cytoprotective, and anti-inflammatory effects, and have a role in the apoptosis of many tumours [13-15]. IGF-1 is decreased in rheumatoid arthritis and juvenile idiopathic arthritis because its synthesis is inhibited by inflammation [16]. IGFBPs may present biological functions with IGF-dependent and IGF-independent action. The underlying mechanisms mediating these biological actions of IGFBPs are largely unknown. IGFBPs may be mediated through cell surface receptors.

The molar IGF-1/IGFBP-3 ratio as an index for IGF-1 availability is used to investigate different conditions such as predicting the ovarian cancer risk, predicting the initiation of colorectal cancer, breast cancer risk, providing additional non-invasive markers in HCV-related liver injury and insulin sensitivity in patients with type 2 diabetes, and cardiovascular events in recent studies [17-24]. IGFBP-3 may have therapeutic potential in RA [16]. It has been concluded that patients with BS exhibit peripheral insulin resistance; and this could be explained as diverse consequences of inflammation and endothelial dysfunction $[6,7,25]$.

\section{Aim}

In the present study, we have investigated the role of IGF-1, IGFBP-3, and IGF-1/IGFBP-3 ratio in BS.

\section{Material and methods}

Forty patients (20 active and 20 remission criteria), who were diagnosed with BS, according to Japanese criteria were enrolled in this study. The patients were recruited from the Yıldırım Beyazıt University Yenimahalle Training and Research Hospital. Smoking and alcohol consumption, chronic disease (primary/secondary hypertension, diabetes mellitus, coronary arterial disease, heart/liver/renal failure, $B_{12}$ and folic acid deficiency), history of trauma in last 15 days, acute and chronic inflammatory disease, and drug abuse were considered as exclusion criteria.

Age and sex of the patients were recorded. Physical examination was performed and BS patients were divided into 2 subgroups of active and remission. Active or remission criteria were used according to clinical criteria defined by Bayazıt et al. Active criteria were as follows: one or more oral aphthae presented in the last week, genital aphthae presented in the last 2 weeks, erythema nodosum like skin lesions presented in the last 2 weeks, and specific eye and organ involvement in the last week [1, 2].

\section{Ethical status}

The approval of the Yıldırım Beyazıt University ethics committee was obtained (2017-07-02).

\section{Blood samples}

Blood samples were collected and separated sera were stored in $-80^{\circ} \mathrm{C}$ until processed.

\section{Biochemistry analyses}

IGF-1 DRG (DRG International Inc., USA) and IGFBP-3 DIAsource (DIAsource ImmunAssays S.A, Belgium) Elisa Kit, a solid phase enzyme-linked immunoabsorbent assay based on the principle of competitive binding, were used. ESR levels were estimated using an automated method (Alifax, Padova, Italy).

\section{Statistical analysis}

Kolmogorov Smirnov test was used to determine, whether the distribution of continuous variables were normal or not. Levene test was used for the evaluation of the homogeneity of variances. The continuous variables were shown as mean \pm SD or median $\left(25^{\text {th }}-75^{\text {th }}\right)$ percentiles, and the number of cases and percentages were used for categorical data.

While the mean differences between the control and Behçet's disease groups were compared by Student's $t$ test, Mann Whitney $U$ test was applied for the comparison of data with non-normal distribution. The comparison of more than two independent groups was analysed by one-way ANOVA or Kruskal Wallis test, where appropriate. When the $p$-value from One-Way ANOVA or Kruskal Wallis test statistics were statistically significant, post-hoc Tukey HSD or Conover's multiple comparison test were used to determine which group was different from others. Categorical data were evaluated by Pearson's $\chi^{2}$ or continuity corrected $\chi^{2}$ test, where applicable. Degrees of association between continuous variables were evaluated by Spearman's Rank Correlation analyses.

The continuity of the differences in laboratory measurements (i.e. IGFBP-3, IGF-1 and IGF-1/IGFBP-3) between control and patient groups was evaluated by multiple linear regression analyses after adjusting for all possible confounding factors. Any variable with a $p$-value of $<0.10$ in univariable test was accepted as a candidate for the multivariable model along with all variables with known clinical importance. Coefficient of regression and 95\% confidence interval for each independent variable were also calculated.

Data analysis was performed by using IBM SPSS Statistics version 17.0 software (IBM Corporation, Armonk, NY, USA). P-value of less than 0.05 was considered statistically significant.

\section{Results}

There were no differences between the control and BS groups as to mean age and gender distribution ( $p=$ 0.347 and $p=1.000$, respectively). The mean body mass index (BMI) levels were also similar between the two groups $(p=0.249)$. Half of the patients had active dis- 
ease and the other half were in remission. There were no statistical differences between the control group, active $\mathrm{BS}$ and remission BS according to average age, gender, and BMI, respectively ( $p=0.642, p=0.932, p=0.313)$. These results are summarized in Table 1.

Results of blood levels belonging to active and remission Behçet's groups and comparison with the control group are shown in Table 1.

There were no statistical differences between active and remission BS as to mean disease duration, lipid profiles, active organ involvement, and administration of therapy $(p>0.05)$. In the Behçet's group, the erythrocyte sedimentation rate (ESR) and high sensitive C-reactive protein (hs-CRP) levels were statistically higher compared to the control group $(p<0.001)$.

The ESR levels were statistically higher in active and remission Behçet's groups compared to the control group $(p=0.004$ and $p<0.001)$. The ESR levels were statistically higher in active Behçet's group compared to the remission Behçet's group ( $p<0.001)$. Hs-CRP levels were higher in the active Behçet's group and the remission Behçet's group compared to the control group $(p<0.001$ and $p<0.001$, respectively). Hs-CRP levels were higher in the active Behçet's group than the remission Behçet's group $(p<0.001)$. The levels of mean IGFBP3 were higher in BS than in the control group, and mean IGF-1 and molar IGF-1/IGFBP3 ratio was lower in BS in a statistically significant manner compared to the control group $(p<0.001)$.

In Figure 1, IGF-1 and IGFBP-3 levels in control and active- remission $\mathrm{BS}$ groups are given.

\section{IGF-1 levels}

Mean IGF-1 levels were low in both active BS $(p<$ $0.001)$ and remission $\mathrm{BS}(p=0.030)$, compared to the

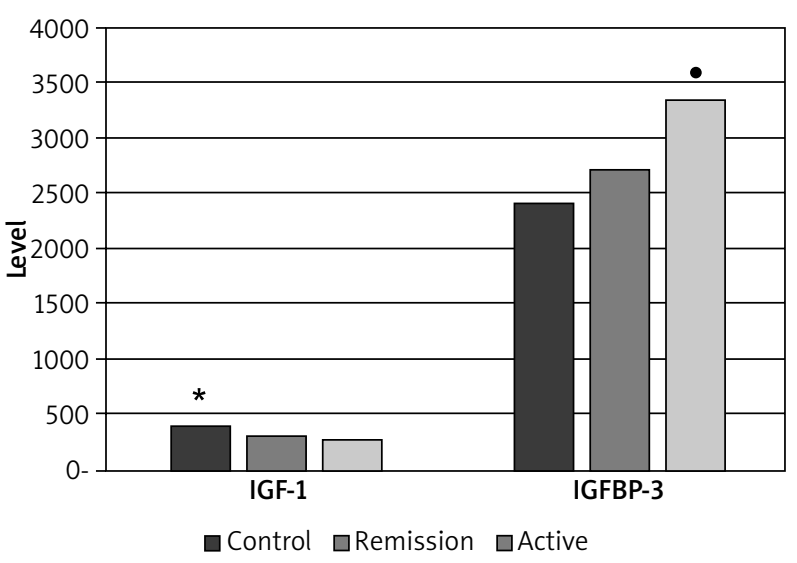

${ }^{*} p<0.05$ Control group levels higher than remission and active BS, $\cdot p<0.001$ Active BS levels higher than remission BS and control group.

Figure 1. IGF-1 and IGFBP-3 levels in control, active and remission groups

control group (Figure 1) and mean IGF-1 levels were similar between active BS and remission BS $(p=0.467)$.

IGF-1 levels were lower than the healthy controls both in the active BS ( $\mathrm{B}=-168.546,95 \% \mathrm{Cl}$ : -300.120 --36.972 and $p=0.013)$ and the remissions $B S(B=$ $-107.475,95 \% \mathrm{Cl}:-192.580--22.370$ and $p=0.014)$ that IGF-1 level was an independent factor in BS of both ESR and hs-CRP ( $\mathrm{B}=-108.98,95 \% \mathrm{Cl}:-193.508--22.687$ and $p=0.014)$ (Tables 2, 3).

\section{IGFBP-3 levels}

The levels of mean IGFBP3 were not statistically different between the control group and the remission group of BS ( $p=0.453)$. In active BS, mean IGFBP-3 levels

Table 1. Clinic (ESR, hs-CRP, IGF-1, IGFBP-3, IGF-1/IGFBP-3 values for all groups) and demographic values of all groups

\begin{tabular}{lcccccc}
\hline Parameter & Controls $(n=20)$ & Patients $(n=40)$ & $P$-value $^{\mathrm{a}}$ & Remission $(n=20)$ & Active $(n=20)$ & $P$-value ${ }^{\mathrm{b}}$ \\
\hline Age [years] & $37.0 \pm 10.4$ & $39.6 \pm 10.0$ & 0.347 & $39.4 \pm 10.0$ & $39.8 \pm 10.2$ & 0.642 \\
\hline Female gender & $12(60.0 \%)$ & $25(62.5 \%)$ & 1.000 & $13(65.0 \%)$ & $12(60.0 \%)$ & 0.932 \\
\hline BMI $\left[\mathrm{kg} / \mathrm{m}^{2}\right.$ ] & $25.8 \pm 3.7$ & $27.1 \pm 4.2$ & 0.249 & $26.5 \pm 4.2$ & $27.8 \pm 4.3$ & 0.313 \\
\hline $\begin{array}{l}\text { Duration of disease } \\
\text { [months] }\end{array}$ & - & $60.0(36.0-148.5)$ & - & $84.0(37.0-192.0)$ & $54.0(18.7-114.0)$ & 0.114 \\
\hline Organ involvement & - & $25(62.5 \%)$ & - & $10(50.0 \%)$ & $15(75.0 \%)$ & 0.191 \\
\hline Treatment receiving & - & $30(75.0 \%)$ & - & $13(65.0 \%)$ & $17(85.0 \%)$ & 0.273 \\
\hline ESR & $7.6 \pm 5.3^{\mathrm{A}, \mathrm{B}}$ & $24.0 \pm 11.4$ & $<0.001$ & $15.3 \pm 8.7^{\mathrm{A}, \mathrm{C}}$ & $30.7 \pm 9.7^{\mathrm{B}, \mathrm{C}}$ & $<0.001$ \\
\hline Hs-CRP & $0.83 \pm 0.34^{\mathrm{A}, \mathrm{B}}$ & $3.66 \pm 1.3$ & $<0.001$ & $3.32 \pm 1.1^{\mathrm{A}, \mathrm{C}}$ & $5.77 \pm 1.2^{\mathrm{B}, \mathrm{C}}$ & $<0.001$ \\
\hline IGFBP-3 & $2427.4 \pm 431.1^{\mathrm{B}}$ & $3044.1 \pm 961.4$ & $<0.001$ & $2729.4 \pm 513.0^{\mathrm{C}}$ & $3358.9 \pm 1193.9^{\mathrm{B}, \mathrm{C}}$ & 0.002 \\
\hline IGF-1 & $404.0 \pm 106.3^{\mathrm{A}, \mathrm{B}}$ & $285.3 \pm 122.3$ & $<0.001$ & $307.2 \pm 109.8^{\mathrm{A}}$ & $263.4 \pm 132.8^{\mathrm{B}}$ & $<0.001$ \\
\hline IGF-1/IGFBP-3 & $0.17 \pm 0.063^{\mathrm{A}, \mathrm{B}}$ & $0.10 \pm 0.046$ & $<0.001$ & $0.12 \pm 0.041^{\mathrm{A}}$ & $0.08 \pm 0.047^{\mathrm{B}}$ & $<0.001$
\end{tabular}

${ }^{a}$ The comparison between the control and patient group, ${ }^{b}$ the comparison among the control, remission and active disease groups. ${ }^{A} \mathrm{Con}$ trol vs. remission $(p<0.05),{ }^{B}$ Control vs. active $(p<0.001)$, Cremission vs. active $(p<0.05)$. ESR - erythrocyte sedimentation rate, hs-CRP-high sensitive C-reactive protein, IGFBP-3 - insulin-like growth factor binding protein-3, IGF-1 - insulin-like growth factor-1, IGF-1/IGFBP-3 - insulin-like growth factor-1/insulin-like growth factor binding protein-3 ratio. 
Table 2. IGF-1, IGFBP-3 and IGF-1/IGFBP-3 levels and correlation with other factors (remission Behçet, active Behçet, ESR, hs-CRP)

\begin{tabular}{lccc}
\hline Parameter & $\begin{array}{c}\text { Coefficient of } \\
\text { regression }\end{array}$ & $\begin{array}{c}95 \% \text { Confidence } \\
\text { interval }\end{array}$ & $P$-value \\
\hline IGF-1: & & \\
\hline Remission & -107.47 & $-192.58--22.37$ & 0.014 \\
\hline Active & -168.54 & $-300.12--36.97$ & 0.013 \\
\hline ESR & 0.23 & $-3.71-4.18$ & 0.906 \\
\hline Hs-CRP & 4.66 & $-10.82-20.14$ & 0.549 \\
\hline IGFBP-3: & & & \\
\hline Remission & 138.93 & $-437.77-715.65$ & 0.631 \\
\hline Active & 549.79 & $-339.9-1439.4$ & 0.221 \\
\hline ESR & 7.68 & $-18.86-34.24$ & 0.564 \\
\hline Hs-CRP & 30.25 & $-73.81-134.31$ & 0.562 \\
\hline IGF-1/IGFBP-3: & & & \\
\hline Remission & -0.056 & $-0.094--0.018$ & 0.004 \\
\hline Active & -0.086 & $-0.144--0.028$ & 0.005 \\
\hline ESR & -0.0002 & $-0.002-0.002$ & 0.846 \\
\hline Hs-CRP & 0.001 & $-0.006-0.008$ & 0.836 \\
\hline
\end{tabular}

ESR - erythrocyte sedimentation rate, hs-CRP - high sensitive C-reactive protein, IGFBP-3 - insulin-like growth factor binding protein-3, IGF-1 - insulinlike growth factor-1, IGF-1/IGFBP-3 - insulin-like growth factor-1/insulin-like growth factor binding protein-3 ratio.

Table 4. IGF-1, IGFBP-3 and IGF-1/IGFBP-3 levels and correlation factors with age, BMI, ESR, hs-CRP

\begin{tabular}{lccc}
\hline Parameter & IGF-1 & IGFBP-3 & IGF-1/IGFBP-3 \\
\hline Age: & & & \\
\hline Coefficient of correlation & -0.07 & 0.03 & -0.09 \\
\hline$P$-value & 0.59 & 0.80 & 0.48 \\
\hline BMI: & & \\
\hline Coefficient of correlation & -0.001 & 0.005 & -0.01 \\
\hline$P$-value & 0.99 & 0.97 & 0.94 \\
\hline ESR: & & & \\
\hline Coefficient of correlation & -0.29 & 0.44 & -0.43 \\
\hline$P$-value & 0.024 & $<0.001$ & $<0.001$ \\
\hline Hs-CRP: & & & \\
\hline Coefficient of correlation & -0.23 & 0.43 & -0.39 \\
\hline$P$-value & 0.07 & $<0.001$ & 0.002
\end{tabular}

IGF-1 - insulin-like growth factor-1, IGFBP-3 - insulin-like growth factor bind ing protein-3, IGF-1/IGFBP-3 - insulin-like growth factor-1/insulin-like growth factor binding protein-3 ratio, BMI - body mass index, ESR - erythrocyte sedimentation rate, hs-CRP - high sensitive C-reactive protein.

were statistically higher than in the control group and the remission $\mathrm{BS}$ ( $p<0.001$ and $p=0.038$, respectively) (Figure 1). There was a statistical and positive correlation between levels of ESR and IGFBP-3 $(r=0.440$ and $p<0.001)$ and there were similar correlations between
Table 3. The effect of Behçet's syndrome on IGF-1, IGFBP-3, and IGF-1/IGFBP-3 levels according to multivariate analyses

\begin{tabular}{lccc}
\hline Parameter & $\begin{array}{c}\text { Coefficient } \\
\text { of regression }\end{array}$ & $\begin{array}{c}\text { 95\% Confidence } \\
\text { interval }\end{array}$ & P-value \\
\hline IGF-1: & -108.09 & $-193.50--22.68$ & 0.014 \\
\hline Behçet's & -0.97 & $-4.39-2.44$ & 0.570 \\
\hline ESR & 1.59 & $-13.07-16.27$ & 0.828 \\
\hline Hs-CRP & & & \\
\hline IGFBP-3: & 141.59 & $-437.26-720.44$ & 0.626 \\
\hline Behçet's & 15.79 & $-7.17-38.77$ & 0.174 \\
\hline ESR & 50.84 & $-47.81-149.50$ & 0.306 \\
\hline Hs-CRP & & & \\
\hline IGF-1/IGFBP-3: & -0.056 & $-0.094--0.018$ & 0.004 \\
\hline Behçet's & -0.001 & $-0.002-0.001$ & 0.319 \\
\hline ESR & -0.001 & $-0.007-0.006$ & 0.810 \\
\hline Hs-CRP & & &
\end{tabular}

ESR - erythrocyte sedimentation rate, hs-CRP - high sensitive C-reactive protein, IGFBP-3 - insulin-like growth factor binding protein-3, IGF-1 - insulinlike growth factor-1, IGF-1/IGFBP-3 - insulin-like growth factor-1/insulin-like growth fa ctor binding protein-3 ratio.

the hs-CRP levels and IGFBP-3 levels $(r=0.430$ and $p<0.001$ ) (Table 4).

IGFBP-3 levels were not a useful marker for predicting the activation and remission of BS according to multiple linear regression analyses after being adjusted for all possible confounding factors ( $p=0.631$ and $p=0.221$ ).

\section{IGF-1/IGFBP-3 ratio}

According to the control group, mean IGF-1/IGFBP-3 levels were lower in the active BS $(p<0.001)$ and the remission $\mathrm{BS}(p=0.002)$, and mean IGF-1/IGFBP-3 levels were similar between the active BS and the remission BS $(p=0.146)$.

IGF-1/IGFBP-3 ratio was a predictive factor for BS and it was an independent factor in BS both in inactive $(\mathrm{B}=-0.056,95 \% \mathrm{Cl}:-0.094--0.018$ and $p=0.004)$ and active patients $(\mathrm{B}=-0.086,95 \% \mathrm{Cl}:-0.144--0.028$ and $p=0.005)$. IGF-1/IGFBP-3 ratio was lower in BS than in the control group and it was an independent factor with respect to ESR and hs-CRP (B $=-0.056,95 \% \mathrm{Cl}$ : $-0.094-$ -0.018 and $p=0.004$ ) (Table 3).

There were no differences with regard to sex, BS treatment, and systemic organ involvement in the levels of IGFBP3 and IGF-1, and IGF-1/IGFBP-3 ratio $(p>0.05)$ as shown in Table 5.

\section{Discussion}

Behçet's syndrome is a chronic recurrent systemic inflammatory disease. The symptoms are observed concurrently or in different time periods. The site and timing of activation periods could not be predicted. Behçet's syn- 
drome is characterized by recurrent attacks affecting the mucocutaneous tissues, eyes, joints, blood vessels, brain, and gastrointestinal tract. It is a multifactorial disease that affects variable vessel vasculitis.

Metabolic syndrome (MetS) is characterized by central obesity, elevated triglycerides (TG), reduced highdensity lipoproteins (HDL), impaired fasting blood glucose (FBG), and hypertension. Yalçın et al. suggested that all BS patients should be closely monitored for hypertension, hyperlipidaemia, and diabetes mellitus to avoid MetS development [25]. It has been concluded that patients with BS exhibit peripheral insulin resistance; and this could be explained as the diverse consequences of inflammation and endothelial dysfunction.

Insulin-like growth factor-1 is the major member of the insulin-like growth factor family and it is considered to exert anabolic effects and to mediate the proliferation of multiple tissues. Hepatocytes are the major source of circulating IGF-1 [26-29]. IGF-1 can be produced locally by many types of peripheral cells under basal conditions, as well as in response to inflammation. In this case, IGF-1 acts as an autocrine or a paracrine factor like many cytokines and growth factors. The IGFBPs transport IGF-1 in the bloodstream and exhibit unique biological actions, including cell growth inhibition or promotion and induction of apoptosis. IGFBP-3 is the most abundant form, with the highest affinity for IGF-1. Less than 1\% of IGF-1 circulates in free form in the bloodstream. Low IGF-1 levels were observed in chronic diseases and malnutrition while IGFBP-3 remained relatively unchanged [13-15, 27].

In the present study, mean IGF-1 levels were lower in the active BS $(p<0.001)$ and the remission BS $(p=0.030)$ compared to the healthy control group. This may be due to the increase in IGFBP-3 levels in BS. The reason of this is that a high level of IGFBP-3 reduces IGF-1 action, while decreasing free IGF-1 level, as it is known.

IGFBP-3 is also produced by peripheral tissues and can be upregulated by a variety of molecules, such as $\mathrm{GH}, \mathrm{IL}-1, \mathrm{TNF}-\alpha$, transforming growth factor- $\beta 1$, glucocorticosteroids, retinoic acid, vitamin D, antioestrogens, and antiandrogens [30, 31]. The levels of circulating IGF-1 and IGFBP-3 are affected by several factors, such as age, hormones, nutrition, and comorbidities [15]. In the present study, mean age and demographical features were also similar in each group. Some authors have suggested that inflammatory markers and IGF-1 and IGFBP-3 levels differ in obesity [28, 29]. In our study, BMI levels were similar between the groups and did not have an effect on the IGF-1 levels and IGF-1/IGFBP-3 ratio $(p>0.05)$. The conclusion was that the presence of large amounts of IGFBP-3 caused a reduction in the free IGF levels, while small amounts of IGFBP-3 protected IGFs, intensifying their effects.

Systemic inflammation was marked by higher levels of hs-CRP and both higher levels of $\mathrm{GH}$ and lower levels of IGF-1 and IGFBP-3. In turn, higher GH and lower
Table 5. IGF-1, IGFBP-3 and IGF-1/IGFBP-3 levels according to gender, organ involment and treatment receiving

\begin{tabular}{|c|c|c|c|c|}
\hline Parameter & $N$ & IGF-1 & IGFBP-3 & IGF-1/IGFBP-3 \\
\hline \multicolumn{5}{|l|}{ Gender: } \\
\hline Female & 37 & $318.2 \pm 137.4$ & $2973.1 \pm 983.0$ & $0.12 \pm 0.064$ \\
\hline Male & 23 & $335.6 \pm 117.2$ & $2622.1 \pm 607.3$ & $0.14 \pm 0.059$ \\
\hline$P$-value & & 0.616 & 0.130 & 0.246 \\
\hline \multicolumn{5}{|c|}{ Organ involvement: } \\
\hline No & 15 & $273.7 \pm 110.9$ & $2725.7 \pm 555.2$ & $0.11 \pm 0.044$ \\
\hline Yes & 25 & $292.3 \pm 130.4$ & $3235.2 \pm 1104.8$ & $0.10 \pm 0.048$ \\
\hline$P$-value & & 0.648 & 0.105 & 0.619 \\
\hline \multicolumn{5}{|c|}{ Treatment receiving: } \\
\hline No & 10 & $272.4 \pm 123.4$ & $2779.8 \pm 602.8$ & $0.10 \pm 0.044$ \\
\hline Yes & 30 & $289.6 \pm 123.8$ & $3132.3 \pm 1047.8$ & $0.10 \pm 0.048$ \\
\hline$P$-value & & 0.705 & 0.322 & 0.965 \\
\hline
\end{tabular}

ESR - erythrocyte sedimentation rate, $h \mathrm{~s}-C R P$ - high sensitive C-reactive protein, IGFBP-3 - insulin-like growth factor binding protein-3, IGF-1 - insulinlike growth factor-1, IGF-1/IGFBP-3 - insulin-like growth factor-1/insulin-like growth factor binding protein-3 ratio.

IGFBP-3 levels were associated with a shorter stature. These findings are consistent with a model of inflammation driving hepatic resistance to $\mathrm{GH}$ signalling as noted in preclinical studies. Similarly, reduction in serum IGF-1 by dietary restriction in animal models slows tumour progression and increases apoptosis in tumour cell effects that are both reversed by infusions of recombinant IGF-1 [15].

IGF-1 levels were lower in BS and it was an independent factor of ESR and hs-CRP (a diagnostic predictive factor) ( $\mathrm{B}=-108.098,95 \% \mathrm{Cl}:-193.508--22.687$ and $p=0.014)$.

There was an increase in inflammatory markers such as ESR and hs-CRP in both the active and the remission patients. In active patients, these levels were also higher than in the remission patients as expected. There was a positive correlation between these inflammatory cytokines and IGFBP-3 levels, respectively (ESR $r=0.44$, $p<0.001)$, and hs-CRP $(r=0.43$ and $p<0.001)$. There was a statistically significant negative correlation between IGF-1 and ESR ( $r=-0.291$ and $p=0.024)$ and there was no statistically significant correlation between IGF-1 and hs-CRP ( $p>0.05)$. During the regression analyses, it was found that the levels of IGF-1 were lower in $\mathrm{BS}$ and independent of ESR and hs-CRP $(B=-108.098$, $95 \% \mathrm{Cl}:-193.508--22.687$ and $p=0.014)$. The reason may be that the levels of ESR and hs-CRP increase in BS, and these inflammatory markers directly induce (not affect IGF-1) the production of IGFBP-3. Subsequently, IGFBP-3 binds to the free IGF-1 and the level of IGF-1 decreases in the bloodstream. Another mechanism may be due to insulin resistance in BS. IGFBP-3 may be mediated by an unknown trigger through impaired cell surface re- 
ceptors in BS. Insulin also up-regulates IGFBP-3 levels, as known. Otherwise, it may be an unknown immunological mechanism.

In active BS, mean IGFBP-3 levels were statistically higher than in the control group and the remission BS ( $p<0.001$ and $p=0.038$, respectively). The levels of mean IGFBP-3 were not statistically different (were similar) between the control group and the remission group of BS $(p=0.453)$. In the active $\mathrm{BS}$, inflammatory markers such as IL-1, TNF- $\alpha$, TGF- $\beta 1$ were increased, as known, and this inflammatory response might induce the production of IGFBP-3 and its subsequent increase. Therefore, the levels of IGF-1 may decrease in the bloodstream. Nevertheless, during the regression analyses, the effects of IGFBP-3 were not statistically different in the active $(p=0.221)$ and the remission $\mathrm{BS}(p=0.631)$. IGF-1 levels were lower than in the healthy controls and IGF-1 level was an independent factor in BS for both ESR and hs-CRP, both in the active BS ( $B=-168.546$, 95\% Cl: $-300.120--36.972$ and $p=0.013)$ and the remission $B S(B=-107.475,95 \% \mathrm{Cl}$ : $-192.580--22.370$ and $p=0.014)$ according to multiple linear regression analyses after being adjusted for all possible confounding factors. It may be due to inflammation in BS and possible insulin resistance that up-regulates the production of IGF-1 and IGFBP-3; furthermore, IGFBP-3 transports IGF-1 to tissues and causes organ inflammation.

These findings suggest that reduced levels of IGF-1 in circulation and increased blood levels of IGFBP-3 in BS may result in suppression of its anti-inflammatory functions, and therefore IGF-1 may play a diagnostic role to present itself.

The IGF-1/IGFBP-3 ratio was lower in BS in a statistically significant manner as compared to the healthy control group, and the ratio was independent of ESR and hs-CRP.

\section{Conclusions}

We have found that the IGF-1/IGFBP-3 ratio was lower in BS and it was an independent factor of ESR and hsCRP according to multivariate regression analyses. The IGF-1/IGFBP-3 ratio may be a useful parameter for predicting the presence of BS; however, further studies are required on this subject.

\section{Conflict of interest}

The authors declare no conflict of interest.

\section{References}

1. Behçet H. Uber rezidivierende Aphthöse, durch ein Virus verusachte Geschwüre am Mund, am Auge und an den Genitale. Dermatol Wochenschr 1937; 105: 1152.
2. Bayazit N, Yılmaz M, Oral B, et al. Immunologic activation parameters in Behcet's disease. Turk J Dermatol 2008; 2: 34-8.

3. Oguz A, Dogan EG, Uzunlulu M, Oguz FM. Insulin resistance and adiponectin levels in Behcet's syndrome. Clin Exp Rheumatol 2007; 25 (4 Suppl 45): S118-9.

4. Alan S, Tuna S, Turkoglu EB. The relation of neutrophil-tolymphocyte ratio, platelet-to-lymphocyte ratio, and mean platelet volume with the presence and severity of Behcet's syndrome. Kaohsiung J Med Sci 2015; 31: 626-31.

5. Sahin E, Karaman G, Uslu M, et al. Adiponectin levels, insulin resistance and their relationship with serum levels of inflammatory cytokines in patients with Behcet's disease. J Eur Acad Dermatol Venereol 2012; 26: 1498-502.

6. Erdem H, Dinc A, Pay S, et al. Peripheral insulin resistance in patients with Behcet's disease. J Eur Acad Dermatol Venereol 2006; 20: 391-5.

7. Kim SK, Choe JY, Park SH, et al. Increased insulin resistance and serum resistin in Korean patients with Behcet's disease. Arch Med Res 2010; 41: 269-74.

8. Rajaram S, Baylink DJ, Mohan S. Insulin-like growth factorbinding proteins in serum and other biological fluids: regulation and functions. Endocr Rev 1997; 18: 801-31.

9. Bonefeld K, Moller S. Insulin-like growth factor-I and the liver. Liver Int 2011; 31: 911-9.

10. Mallea-Gil MS, Ballarino MC, Spiraquis A, et al. IGF-1 levels in different stages of liver steatosis and its association with metabolic syndrome. Acta Gastroenterol Latinoam 2012; 42: 20-6.

11. Garten A, Schuster S, Kiess W. The insulin-like growth factors in adipogenesis and obesity. Endocrinol Metab Clin North Am 2012; 41: 283-95, v-vi.

12. Cheng CW, Yilmaz OH. IGFBP3 and T1D: systemic factors in colonic stem cell function and diabetic enteropathy. Cell Stem Cell 2015; 17: 379-80.

13. Castilla-Cortazar I, Guerra L, Puche JE, et al. An experimental model of partial insulin-like growth factor-1 deficiency in mice. J Physiol Biochem 2014; 70: 129-39.

14. Genre F, Lopez-Mejias R, Rueda-Gotor J, et al. IGF-1 and ADMA levels are inversely correlated in nondiabetic ankylosing spondylitis patients undergoing anti-TNF-alpha therapy. BioMed Res Int 2014; 2014: 671061.

15. Lee HS, Woo SJ, Koh HW, et al. Regulation of apoptosis and inflammatory responses by insulin-like growth factor binding protein 3 in fibroblast-like synoviocytes and experimental animal models of rheumatoid arthritis. Arthritis Rheumatol 2014; 66: 863-73.

16. Sarzi-Puttini P, Atzeni F, Scholmerich J, et al. Anti-TNF antibody therapy improves glucocorticoid-induced insulin-like growth factor-1 (IGF-1) resistance without influencing myoglobin and IGF-1 binding proteins 1 and 3. Ann Rheum Dis 2006; 65: 301-5.

17. Koegelenberg AS, Schutte R, Smith W, Schutte AE. Bioavailable IGF- 1 and its relationship with endothelial damage in a bi-ethnic population: the SABPA study. Thromb Res 2015; 136: 1007-12.

18. Wang Q, Bian CE, Peng $\mathrm{H}$, et al. Association of circulating insulin-like growth factor 1 and insulin-like growth factor binding protein 3 with the risk of ovarian cancer: a systematic review and meta-analysis. Mol Clin Oncol 2015; 3: 623-8.

19. Mohajeri Tehrani MR, Tajvidi M, Kahrizi S, Hedayati M. Does endurance training affect IGF-1/IGFBP-3 and insulin sensitivity in patients with type 2 diabetes? I Sports Med Phys Fitness 2015; 55: 1004-12. 
20. Jiang B, Zhang $X$, Du LL, et al. Possible roles of insulin, IGF-1 and IGFBPs in initiation and progression of colorectal cancer. World J Gastroenterol 2014; 20: 1608-13.

21. Adamek A, Kasprzak A, Mikos H, et al. The insulin-like growth factor- 1 and expression of its binding protein 3 in chronic hepatitis $\mathrm{C}$ and hepatocellular carcinoma. Oncol Rep 2013; 30: 1337-45.

22. Meggiorini ML, Cipolla V, Borgoni G, et al. Possible effects of insulin-like growth factor-I, IGF-binding protein-3 and IGF-1 /IGFBP-3 molar ratio on mammographic density: a crosssectional study. Eur J Gynaecol Oncol 2012; 33: 74-8.

23. Yoon YS, Keum N, Zhang X, et al. Circulating levels of IGF-1, IGFBP-3, and IGF-1/IGFBP-3 molar ratio and colorectal adenomas: a meta-analysis. Cancer Epidemiol 2015; 39: 1026-35.

24. Kong AP, Choi KC, Wong GW, et al. Serum concentrations of insulin-like growth factor-l, insulin-like growth factor binding protein-3 and cardiovascular risk factors in adolescents. Ann Clin Biochem 2011; 48: 263-9.

25. Yalcin B, Gur G, Artuz F, Alli N. Prevalence of metabolic syndrome in Behcet disease: a case-control study in Turkey. Am J Clin Dermatol 2013; 14: 421-5.

26. Juul A. Serum levels of insulin-like growth factor I and its binding proteins in health and disease. Growth Horm IGF Res 2003; 13: 113-70.

27. Mohanraj L, Kim HS, Li W, et al. IGFBP-3 inhibits cytokineinduced insulin resistance and early manifestations of atherosclerosis. PLoS One 2013; 8: e55084.

28. Ben Ounis O, Elloumi M, Zouhal $\mathrm{H}$, et al. Effect of individualized exercise training combined with diet restriction inflammatory markers and IGF-1/IGFBP-3 in obese children. Ann Nutr Metab 2010; 56: 260-6.

29. Faupel-Badger JM, Berrigan D, Ballard-Barbash R, Potischman N. Anthropometric correlates of insulin-like growth factor 1 (IGF-1) and IGF binding protein-3 (IGFBP-3) levels by race/ethnicity and gender. Ann Epidemiol 2009; 19: 841-9.

30. Underwood LE, Thissen JP, Lemozy S, et al. Hormonal and nutritional regulation of IGF-I and its binding proteins. Horm Res 1994; 42: 145-51.

31. Smith WJ, Underwood LE, Clemmons DR. Effects of caloric or protein restriction on insulin-like growth factor-I (IGF-I) and IGF-binding proteins in children and adults. J Clin Endocrinol Metab 1995; 80: 443-9. 